OPEN ACCESS

Edited by:

Robinson W. (Wally) Fulweiler, Boston University, United States

Reviewed by: lgor Linkov,

United States Army Corps of Engineers, United States

Nova Mieszkowska

University of Liverpool,

United Kingdom

*Correspondence:

Paul A. Sandifer

sandiferpa@cofc.edu

Specialty section:

This article was submitted to Global Change and the Future Ocean,

a section of the journal

Frontiers in Marine Science

Received: 21 November 2020

Accepted: 16 February 2021

Published: 15 March 2021

Citation:

Sandifer PA and Scott Gl (2021)

Coastlines, Coastal Cities,

and Climate Change: A Perspective

on Urgent Research Needs

in the United States.

Front. Mar. Sci. 8:631986.

doi: 10.3389/fmars.2021.631986

\section{Coastlines, Coastal Cities, and Climate Change: A Perspective on Urgent Research Needs in the United States}

\author{
Paul A. Sandifer ${ }^{1 *}$ and Geoffrey I. Scott ${ }^{2}$ \\ ${ }^{1}$ Center for Coastal Environmental and Human Health, College of Charleston, Charleston, SC, United States, ${ }^{2}$ Department \\ of Environmental Health Sciences, Arnold School of Public Health, University of South Carolina, Columbia, SC, United States
}

This paper builds upon Friedman et al. (2020) and other reviews and statements but provides an explicit focus on research needed to improve the resilience and survivability of coastal communities as they face existential threats from climate change. It does not attempt a prescriptive analysis of potential research emphases, but instead recommends some key research areas that we believe will help provide a solid foundation for community adaptation. Our perspective is based on our experiences over a combined nearly 95 years of work in research, management, and policy, much of it related to coastal environments and their communities, rather than expert deliberation within a large group or a systematic review. We present a list of 25 research priorities binned into 12 categories and targeted to leaders of coastal communities, interested researchers, funders, students, and the public. These priorities are intended to help start more discussion of research needs with and within communities, and help focus attention of researchers on actions that have potential to identify critical decision points and make positive differences for communities. We conclude that priority research should be undertaken with urgency and a much greater level of trans- and interdisciplinarity and community-participatory approaches than yet seen.

Keywords: climate change, research priorities, coastal cities, coastal communities, coastlines, interdisciplinarity

\section{INTRODUCTION}

Coastal lands and waters are where the greatest number of people, very high levels of investment in built infrastructure, and perhaps the most ecological resources are in danger from global climate change. In the United States, coastal shoreline counties (those with a shoreline on the ocean, Gulf of Mexico, or Great Lakes or that contain FEMA-identified areas at high risk for tidal and/or storm surge flooding) are home to $39 \%$ of U.S. residents (123.3 million people in 2010). Coastal 
watershed counties are those that lie immediately behind the shoreline counties. Together, coastal shoreline and watershed counties encompass 52\% of the U.S. population (total of 163.8 million people in 2010) (NOAA, 2013), with a population density three to four times the average elsewhere in the country. In addition, coastal states generally have a disproportionately larger population of potentially vulnerable senior citizens compared to more inland states (NOAA, 2013).

Despite warnings of climate-related dangers to coastal communities and people, no trend toward retreat or even reduced population growth in these areas has been observed yet, and instead increased population growth is anticipated (NOAA, 2013). In addition, most of the largest cities in the United States and the world are located along coastal margins, and these are expected to grow in population by $25 \%$ by 2050 (Aerts et al., 2014). Further, $>80 \%$ of global trade passes through major ports located in coastal areas (Scott et al., 2006, 2012; UN (United Nations), 2017). Many coastal areas are already seeing increasing negative effects of climate change, especially from sea level rise (Sweet et al., 2019; Sinay and Carter, 2020), and more coastal communities are expected to be impacted in the future (Neumann et al., 2015). Because of concerns related to present and future impacts of sea level rise on defense installations, Hall et al. (2016) conducted scenario analyses of vulnerability of 1,774 coastal facilities around the world for the U.S. Department of Defense, in preparation for actions to improve resiliency of such installations as the world faces a variety of possible climate change futures. More recently, a "think tank" of distinguished retired and former national security, military, and intelligence professionals analyzed a range of climate futures and concluded that "...even at scenarios of low warming, each region of the world will face severe risks to national and global security in the next three decades. Higher levels of warming will pose catastrophic, and likely irreversible, global security risks over the course of the 21st century" (Guy et al., 2020).

In this perspective, we propose components of a research agenda that, if undertaken even in part, could measurably improve the resilience, survivability, and sustainability of coastal communities and reduce risks and vulnerabilities as they face increasingly impactful effects of climate change. These concepts have a wide range of meanings in different contexts and as used by researchers and practitioners across a diversity of fields. Resilience in particular has such a broad range of meanings that different fields may eventually adopt different conceptualizations of the term (Linkov et al., 2018). Here we have chosen to follow the definitions of resilience and sustainability provided by Galaitsi et al. (2020) to wit: resiliency is the "capacity to recover critical functions and adapt following a disruptive event," and sustainability is the "ability to maintain a high level of functionality without inputs from external resources." Risk can also take different meanings. In the context of government regulation and in risk assessment work, risk is typically defined as risk $=$ threat $\times$ vulnerability $\times$ consequences, and there are different levels or tiers of risk that can be calculated for various purposes and needs (Linkov et al., 2018). Here we use risk and vulnerability in their more basic forms as the threat of harm and heightened likelihood of experiencing harm, respectively. We also include in risk the concept of "social amplification" as described by Renn (2008) to mean both the intensification and diminishment of perceptions of risk based on individual and socio-economic-cultural factors. Similarly, we use survivability to mean the ability to survive, to continue to exist when facing a life- or existence-challenging circumstance. New or improved definitions of risk, vulnerability, and survivability were not included in Galaitsi et al. (2020).

Many factors individually and in combination affect the vulnerability of coastal and island communities and facilities to climate change. These include the following (in no particular order): (a) economic and social resources; (b) density of development and population, including of senior citizens who may have underlying health issues and minority populations who often reside in locations where air pollution may contribute to disease susceptibility (Rosenbaum et al., 2011; Millett et al., 2020); (c) elevation; (d) rate of locally apparent sea level rise; (e) history of and likely future exposure to hurricanes and other extreme weather, harmful algal blooms, oil spills, chemical contamination, and other dangerous events; (f) status of and protection for critical infrastructure; (g) highly porous soils and subsidence; (h) availability of affordable property insurance; (i) governmental policies and regulations; and ( $\mathrm{j}$ ) effective community leadership.

Friedman et al. (2020) presented a list of 46 research priorities organized into nine priority research areas for "achieving healthy marine ecosystems and human communities in a changing climate." While focused equally on humans and nature and not specifically to coastal communities, their work provides a wealth of food for thought and action and provided an initial foundation for the present perspective. These authors concluded that "the complexity of coupled social-ecological systems has left many potential solutions unidentified or insufficiently explained. The urgent need to achieve positive social and ecological outcomes across local and global scales necessitates rapid and targeted multidisciplinary research to identify solutions that have the greatest chance of promoting benefits for both people and nature." They highlighted that "the potential for transformational change lies in meaningful engagement at the intersections of traditionally distinct disciplines and sectors." Similarly, Portier et al. (2010) provided a comprehensive list of research needs related to health and disease aspects of climate change and emphasized the necessity for an integrated, interdisciplinary approach.

\section{METHODS/APPROACH}

The present paper is the authors' perspective and not a comprehensive or systematic literature review. The list of research areas and questions presented here was adapted, modified, and extended in part from Table 1 in Friedman et al. (2020) to focus specifically on critical research needs for coastal communities, especially in the United States but with likely application elsewhere as well. In addition to this 
foundational work, we identify other recent papers that helped inform our choices of research priorities and categories for "binning" them. We found all of the research bins presented by Friedman et al. (2020) useful constructs, but they did not encompass some other areas we identified as important for coastal communities. Thus, here we include their nine bins, three of which we modified, and three new ones: Modeling, Potential for Managed Coastal Retreat, and Coastal Disease Threats and Health Benefits. All research recommendations based on Friedman et al. (2020) were modified, some extensively, and 11 of the 25 numbered research questions/groups of questions we present are mostly or completely new to this paper and supported by the literature cited. We emphasize research questions that, if pursued, are likely to provide information that could be used to enhance the survivability and resilience of coastal communities, that is, communities' abilities to remain viable in the face of climate change challenges and to recover and adapt following disruptive climate change effects. The presentation sequence is not intended to convey any order of priority or significance (thus the design of Figure 1). Also, the questions posed are not intended to be prescriptive, but rather to serve as a starting point for detailed discussion and planning of research projects and programs targeted to climate change issues facing coastal communities, including those communities that suffer economic and/or cultural disparities.

The research priorities and questions included here were influenced by the work of Friedman et al. (2020) as noted, and also by other researchers as cited, but our perspective, choices, wording, and additions reflect important differences based on our combined $\sim 95$ years of experience in research, management, and policy. Target audiences for these recommendations include municipal, county, state, and other officials and practitioners charged with development and implementation of plans and policies to deal with climate change effects on their communities; natural and social science researchers from numerous disciplines who are committed to working together to provide actionable information to community leaders; public and philanthropic funding entities at international, federal, state, and local levels; and interested members of the public. We also expect that students, particularly those in or entering graduate school and considering research projects that have potential to make a difference for society, will find the suggestions useful.

\section{RESULTS/FINDINGS}

\section{Coastal Climate Change Research Priorities}

$\mathrm{S}=$ same as in Friedman et al. (2020); $\mathrm{M}=$ minor to significant modification from Friedman et al. (2020); and $N=$ new for this paper (Figure 1).

\section{Individual, Cultural, Community, and Ecological Health (M)}

1. What key human, community, and environmental health metrics should be measured, why, and how should they be monitored over time to prepare for and respond to climate change? What should a healthy coastal community look like after adaptation to climate change? What are the key components of social equity that should be addressed in helping coastal communities to adapt to climate change? What interventions related to climate change will provide most benefits for the health of humans and nature? How could citizen science be mobilized and supported to fill data gaps, inform model development, track progress toward adaptation, and improve community involvement (Moss et al., 2019; Nichols et al., 2019)? (some M, mostly N)

2. How could greater engagement and empowerment of women and minorities improve potential for effective implementation of climate change adaptation and mitigation measures in coastal communities? (M)

3. What potential synergies among ecological, individual, community, and cultural health could be harnessed most effectively for climate change adaptation and mitigation? (M)

4. How will climate change affect dynamics and feedback within social and ecological systems separately and in linked socio-ecological systems? (M)

\section{Use Crises to Inform (M)}

5. How can we use global crises, such as the COVID-19 pandemic and its associated health, social, and economic impacts, to inform discussions about likely effects of individual and interacting climate change factors in order to reduce climate change risks to people and coastal communities and catalyze community action? (M)

6. How can we use realized impacts of regional disasters such as major storms, wildfires, oil spills, and the like to inform planning to reduce climate change effects on coastal communities (Sandifer et al., 2020)? (N)

\section{Economics and Financial Incentives (S)}

7. How will overall economic development, including expansion of the "blue economy" (Konar and Ding, 2020), and population growth, interact with climate change impacts to affect how coastal communities adapt to climate change? Which effects/trends could be used to catalyze discovery, invention, design, and implementation of cost-effective mitigation and adaptation measures? (M)

8. What are the most effective ways to scale up possible climate interventions, including uses of natural (SuttonGrier et al., 2018; Silver et al., 2019) and built infrastructure, elevation of housing, ground- and surface-water protective barriers, flood walls, enhancement of "blue carbon" storage in coastal wetlands (Sutton-Grier and Moore, 2016), and others and how can they be incentivized? Which interventions might work best in developed versus developing countries, large versus small cities, islands, deltaic versus other coastal environments? (M, mostly $N$ )

9. What roles should insurance, government-backed and private, and the insurance industry play in development of climate change interventions, including in socioeconomically disadvantaged communities? (N) 


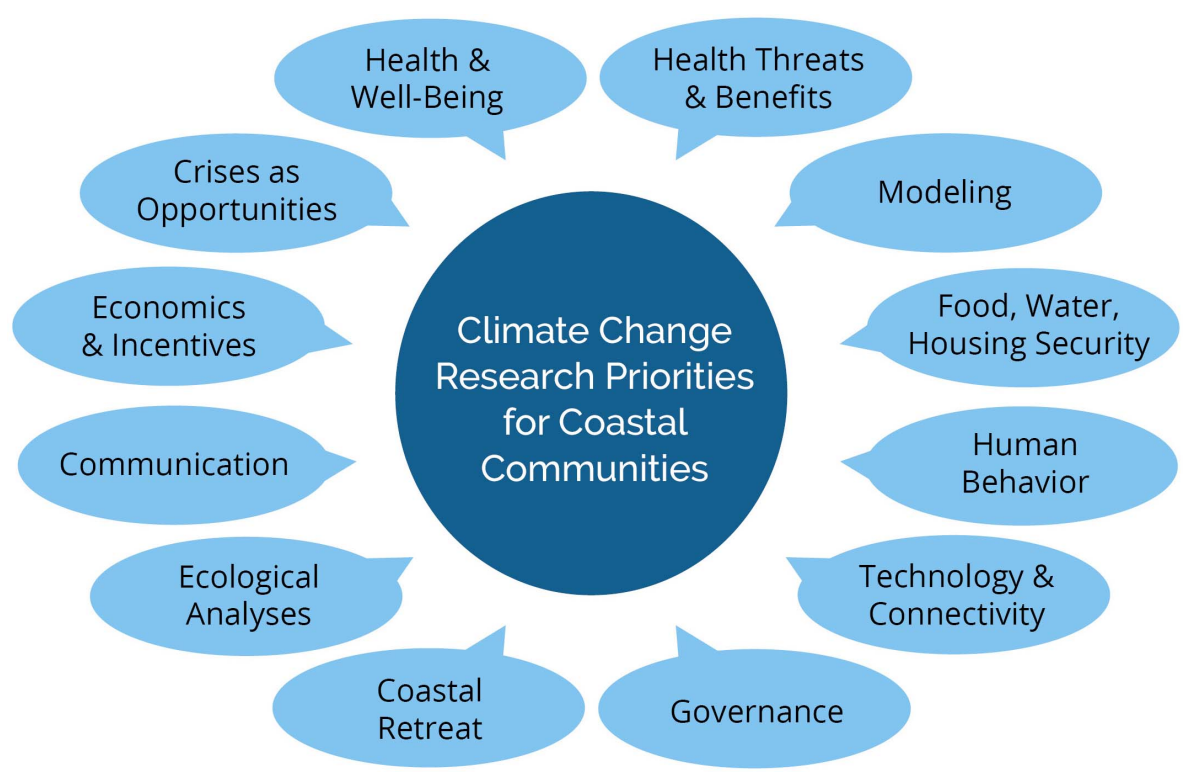

FIGURE 1 | Priority areas for climate change research to increase resilience of coastal communities in the United States and elsewhere.

\section{Effective and Inclusive Communication (S)}

10. How could news and social media be better employed to catalyze policies and actions to enable coastal climate change mitigation and adaptation and to track and report on progress, success, and failures? (M)

11. What are effective communication strategies that take account of cultural and language differences and could be applied to engage the public and increase public support for community-focused climate change mitigation and adaptation actions. (M)

\section{Ecological Analyses (S)}

12. At what point and where will pervasive changes in natural systems or tipping points in ocean circulation, biodiversity, and integrity of ecological systems result in clear and present dangers to humans and coastal communities, including social and economic threats? How do we model, predict, prevent, and prepare for such eventualities? (M)

13. What might future resilient and sustainable coastal communities, i.e., communities able to recover from and adapt to climate change shocks while maintaining functional capacity and integrity, look like and how would they interact with their more or less "natural" surroundings? (M)

\section{Governance (S)}

14. What are the most effective and equitable governance structures for promoting coastal community survivability and resiliency in concert with maintenance of a sustainable environment in the face of climate change effects? (M)

\section{Technology and Increased Connectivity (S)}

15. How can we use our ever-increasing electronic connectivity to promote place-based and communityappropriate solutions to enhance community resilience and sustainability and extend connectivity to those currently underserved? (M)

16. What ecological changes and human health impacts may be associated with technological solutions to coastal climate change problems, and how might these be avoided or mitigated through research and investment? (M)

\section{Human Behavioral Change (S)}

17. What human actions and behaviors contribute most heavily to community risks from climate change and to community abilities to adapt, and how can we discourage the former and encourage the latter? $(\mathrm{M})$

\section{Food, Water, and Housing Security (M)}

18. What actions can be taken to ensure that coastal community residents have and maintain access to secure supplies of nutritious food, water for drinking and sanitary purposes, and adequate housing, in the face of climate change? (M)

\section{Modeling ( $N$ )}

19. How can more integrated models including ensemble models that integrate and combine sea level rise, precipitation, built environment health, and other key factors, be developed to provide more holistic flooding predictions at regional to local scales and 
at temporal scales that allow effective adaptation (Smith et al., 2019)? (N)

20. How can efforts to model climate change effects be coordinated more effectively with, and communicated, to coastal communities and other users (Smith et al., 2019), paying particular attention to the needs of environmental justice and other especially vulnerable communities, to ensure utility of tools at the level of implementation for policy and management decisionmaking? (N)

\section{Potential for Managed Coastal Retreat (N)}

21. What are the potential human health impactspsychological, physical, and cultural-of retreat from coastal communities critically endangered by climate change and how might these be prevented or alleviated? (N)

22. What can be learned from previous retreat and relocation efforts in the United States and elsewhere and how could necessary political, financial, and socio-cultural resources be mobilized to accomplish effective retreat where needed? $(\mathrm{N})$

23. What alternative approaches to retreat, in addition to commonly used property buyouts or small-scale relocations, could be designed, and how might they be incentivized and implemented in socially equitable and environmentally sustainable manners? (N)

\section{Coastal Disease Threats and Health Benefits (N)}

24. How can we minimize health threats to humans from harmful algal blooms, Vibrio bacteria, marine pollution, and other risks that are increasing rapidly in response to rising temperatures, sea level rise, and other global change factors (Fleming et al., 2014; Scott et al., 2019; Landrigan et al., 2020; Sandifer et al., 2021a)? (N)

25. How can we better understand and protect the healthpromoting effects of coastal environments (White et al., 2020) in the face of climate change and use this information to build public support for conservation of natural coastal defenses against storms, flooding, and pollution? (N)

To be successful, research must be conducted within an ongoing interactive, feedback framework where research is planned and conducted with involvement of communities, who also participate in and/or lead development of adaptation policies informed by the research and then put the resulting policies into practice. Applications of research findings should be evaluated at community, regional, and national levels, and outcomes and consequences, both intended and unintended, used as feedback to improve research, policy, and practice (Figure 2). In addition, the United States is a large country encompassing a wide latitudinal range and with communities bordering or in the Atlantic, Gulf of Mexico, Pacific, and Arctic oceans.

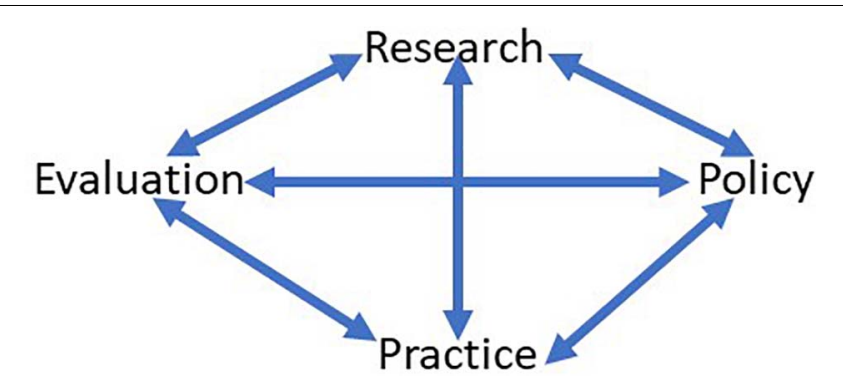

FIGURE 2 | Necessary connections among community-oriented climate adaptation research, policy development and implementation, results and consequences of putting policies into practice, and evaluation and adaptive learning from applications. Bidirectional areas indicate two/multi-way information flows.

Community-applicable research will need to take into account regional and local contexts that may differ considerably from one area to another.

\section{DISCUSSION}

Climate change is now recognized as an existential threat to many coastal cities and communities as they grapple with rapidly increasing flooding, more frequent and intense storms, saltwater intrusion, and other issues directly related to climate change. Potential for exposures to harmful algal bloom toxins and infectious Vibrio bacteria is increasing in geographic extent, frequency, and/or severity (Scott et al., 2019; Sandifer et al., 2021a) as are disasters ranging from hurricanes to floods and wildfires (Anderegg et al., 2020; Sandifer et al., 2020). Multiple land-falling hurricanes occurring in succession within the same region, as has occurred in the Gulf of Mexico in 2020, along with the cumulative impacts on human health from repetitive social disruptions, associated with disaster after disaster and the ongoing COVID-19 pandemic (Sandifer et al., 2020), have amplified concerns of coastal communities. The idea of having coastal communities retreat inland is sometimes seen as a logical solution to the litany of climate change risks to coastal communities. In the abstract, it seems to make sense, and in certain circumstances, there are few if any practical alternatives (Koslov, 2016; Dannenberg et al., 2019; Siders, 2019a). But whether it really is a good social and/or economic option for most coastal communities, at least during the next several decades, is an open question. Siders (2019a) argues persuasively for a national policy and vision for managed retreat as an adaptation tool, but also enumerates major barriers, including a host of Constitutional, psychological, cultural, social, economic, governmental, and other impediments. Her intent was "to provide an agenda for researchers and practitioners working to make retreat a viable option," while recognizing that retreat would not work everywhere. She identified needs for information on approaches and outcomes of current retreat efforts; what successful managed retreat might look like; how retreat 
could be made fairer and more equitable across society, particularly for the already poor and marginalized; alternatives to voluntary buyouts; and how media and government at all levels could be engaged effectively. Similar to the conclusions of Friedman et al. (2020) and the present paper, Siders (2019a) emphasized the necessity for interdisciplinary approaches and research-policy coordination and highlighted critical roles for creativity and leadership.

Based on information and opinions expressed by Mach et al. (2019), Siders (2019a,b), Siders et al. (2019), and others, thorough analyses of the myriad complications and consequences that may be associated with retreat for communities of various sizes and capacities will be essential. A few of the numerous issues that must be examined include policies and financial wherewithal to make retreat possible where it is necessary, where people could go in light of the fact that much if not most of the land immediately behind the coast is already occupied, compensation for loss of financial equity, contamination and other dangers associated with abandoned infrastructure, significant adverse health and cultural impacts to coastal residents, including psychological effects of loss of treasured places and ways of life, the kinds of communities that would be designed and built to receive the migrants, and costs and risks likely to be borne by receiving inland communities, as well as issues of vulnerability, equity, transparency, environmental justice, community participation, and policy (Schlosberg and Collins, 2014; Clement et al., 2015; Mach et al., 2019; Siders, 2019b; Siders et al., 2019; Siders and Keenan, 2020). In some areas, partial retreat could be considered in conjunction with other options. But the public will likely demand that alternatives to retreat first be exhausted, or much more detail developed about how retreat could be accomplished with a minimum of social disruption, before large-scale retreat will become palatable. The bottom line is that much more attention needs to be given to research that will provide answers to the life-anddeath types of questions looming for coastal communities, including those related to retreat. As Siders et al. (2019) concluded: "A substantial amount of innovation and workin both research and practice-will need to be done to make strategic, managed retreat an efficient and equitable adaptation option at scale."

This list of research priorities and questions presented here is intended to help start more discussion of needs with and within communities and sharpen focus of research on actions that have the potential to make positive differences for communities. We anticipate that some of the value of the work will be the separating of what are likely to seem to be huge and intractable problems, with an almost infinite number of entry points or possibilities, into smaller categories and priorities that can be tackled by community leaders and the public as well as scientists. They may also help communities identify critical decision points where residents must take actions, prior to allowing dire circumstances to dictate the need for rapid responses that may be ill-conceived. Conducting the necessary research, communicating the results, and building the public resolve to take essential actions will require a level of interdisciplinarity and integration of natural and social sciences, engineering, land use and urban planning, and robust community-based participatory research approaches, that has not yet been seen. Achieving this level of interdisciplinarity and integration will be wickedly difficult to achieve, but necessary as public trust must be built into this process and trust is best achieved by open, transparent, and multi-directional discussion among community residents, researchers, policy makers, and practitioners. One model for such an approach at a relatively small scale is that being taken by the four Oceans and Human Health Centers currently being supported by the National Institute of Environmental Health Sciences and the National Science Foundation ${ }^{1}$ in the United States. In addition, the types of human health and socio-economic observing systems recommended in Sandifer et al. $(2020,2021 b)$ would provide a wealth of information for use in assessing, preparing for, mitigating, and preventing some of the adverse human and community effects of climate change.

\section{DATA AVAILABILITY STATEMENT}

The original contributions presented in the study are included in the article. Further inquiries can be directed to the corresponding author/s.

\section{AUTHOR CONTRIBUTIONS}

PS: concept, literature review, lead writing, and funding. GS: review and writing, literature, and funding. Both authors contributed to the article and approved the submitted version.

\section{FUNDING}

This work was supported in part by the National Institute of Environmental Health Sciences of the National Institutes of Health under Award Number P01ES028942 to the University of South Carolina and through a subaward to the College of Charleston.

\section{ACKNOWLEDGMENTS}

We thank Dr. Whitney Friedman (National Center for Ecological Analysis and Synthesis, University of California, Santa Barbara) who provided helpful comments on an early draft of the paper and Ms. Catherine Polk who prepared Figure 1. The content is solely the responsibility of the authors and does not necessarily represent the official views of the National Institutes of Health, the University of South Carolina, or the College of Charleston.

\footnotetext{
${ }^{1}$ https://www.niehs.nih.gov/research/supported/centers/oceans/index.cfm
} 


\section{REFERENCES}

Aerts, J. C. H., Wouter Botzen, W. J., Emanuel, K., Lin, N., de Moel, H., and Michel-Kergan, E. O. (2014). Evaluating flood resilience strategies for coastal megacities. Science 344, 473-475. doi: 10.1126/science.124 8222

Anderegg, W. R., Trugman, A. T., Badgley, G., Anderson, C. M., Bartuska, A., Ciais, P., et al. (2020). Climate-driven risks to the climate mitigation potential of forests. Science 368:eaaz7005. doi: 10.1126/science.aaz7005

Clement, V., Rey-Valette, H., and Rulleau, B. (2015). Perceptions on equity and responsibility in coastal zone policies. Ecol. Econ. 119, 284-291. doi: 10.1016/j. ecolceon.2015.09.005

Dannenberg, A. L., Frumkin, H., Hess, J. J., and Ebi, K. L. (2019). Managed retreat as a strategy for climate change adaptation in small communities: public health implications. Clim. Chang. 153, 1-14. doi: 10.1007/s10584-019-02382-0

Fleming, L. E., McDonough, N., Austen, M., Mee, L., Moore, M., Hess, P., et al. (2014). Oceans and human health: a rising tide of challenges and opportunities for Europe. Mar. Environ. Res. 99, 16-19.

Friedman, W. R., Halpern, B. S., McLeod, E., Beck, M. W., Duarte, C. M., Kappel, C. V., et al. (2020). Research priorities for achieving healthy marine ecosystems and human communities in a changing climate. Front. Mar. Sci. 7:5. doi: 10. 3389/fmars.2020.00005

Galaitsi, S., Keisler, J. M., Trump, B. D., and Linkov, I. (2020). The need to reconcile concepts that characterize systems facing threats. Risk Anal. 41, 3-15. doi: $10.1111 /$ risa. 13577

Guy, K., et al. (2020). "A security threat assessment of global climate change: how likely warming scenarios indicate a catastrophic security future", in The Center for Climate and Security, eds F. Femia and C. Werrell (Washington, DC: The Council on Strategic Risks), 86. Available online at: https://climateandsecurity.org/wp-content/uploads/2020/ 03/a-security-threat-assessment-of-climate-change.pdf (accessed February 24, 2021).

Hall, J. A., Gill, S., Obeysekera, J., Sweet, W., Knuuti, K., and Marburger, J. (2016). Regional Sea Level Scenarios for Coastal Risk Management: Managing the Uncertainty of Future Sea Level Change and Extreme Water Levels for Department of Defense Coastal Sites Worldwide. Alexandria, VA: U.S. Department of Defense, Strategic Environmental Research and Development Program, 224.

Konar, M., and Ding, H. (2020). A Sustainable Ocean Economy for 2050 - It's Costs and Benefits. Commissioned by High Level Panel for A Sustainable Ocean Economy. 62. Available online at: https://oceanpanel.org/sites/default/ files/2020-07/Ocean\%20Panel_Economic\%20Analysis_FINAL.pdf (accessed February 22, 2021).

Koslov, L. (2016). The case for retreat. Public Cult. 28:2. doi: 10.1215/089923632427487

Landrigan, P. J., Stegeman, J. J., Fleming, L. E., Allemand, D., Anderson, D. M., Backer, L. M., et al. (2020). Human health and ocean pollution. Ann. Glob. Health 86:1-64. doi: 10.5334/aogh.2831

Linkov, I., Fox-Lent, C., Read, L., Allen, C. R., Arnott, J. C., Bellini, E., et al. (2018). Tiered approach to resiliency assessment. Risk Anal. 38, 1772-1780. doi: $10.1111 /$ risa. 12991

Mach, K. J., Kraan, C. M., Hino, M., Siders, A. R., Johnston, E. M., and Field, C. B. (2019). Managed coastal retreat through voluntary buyouts of flood-prone properties. Sci. Adv. 5:eaax8995. doi: 10.1126/sciadv.aax8995

Millett, G. A., Jones, A. T., Benkeser, D., Baral, S., Mercer, L., Beyrer, C., et al. (2020). Assessing differential impacts of COVID-19 on black communities. Ann. Epidemiol. 47, 37-44. doi: 10.1016/j.annepidem.2020. 05.003

Moss, R. H., Avery, S., Burke, H. M., Chischill, A. M., Dell, J., Fleming, P. A., et al. (2019). A framework for sustained climate assessment in the United States. BAMS (Bull. Am. Meteorol. Soc.) 100, 897-907.

Neumann, B., Vafeidis, A. T., Zimmermann, J., and Nichols, R. J. (2015). Future population growth and exposure to sea-level rise and coastal flooding - a global assessment. PLoS One 10:e0118571. doi: 10.1371/j.pone.0118571

Nichols, C. R., Wright, L. D., Bainbridge, S. J., Cosby, A., Henaff, A., Loftis, J. D., et al. (2019). Collaborative science to enhance coastal resiliencde and adaptation. Front. Mar. Sci. 6:404. doi: 10.3398/fmars.2019.00404
NOAA (2013). National Coastal Population Report. Population Trends from 1970 to 2020. Silver Springs, MD: NOAA, 22.

Portier, C. J., Thigpen Tart, K., Carter, S. R., Dilworth, C. H., Grambsch, A. E., Gohlke, J., et al. (2010). A Human Health Perspective on Climate Change: A Report Outlining the Research Needs on the Human Health Effects of Climate Change. Research Triangle Park, NC: Environmental Health Perspectives. doi: 10.1289/ehp. 1002272

Renn, O. (2008). Concepts of risk: an interdisciplinary review. Part 2: integrated approaches. GAIA 17, 196-204.

Rosenbaum, A., Hartley, S., and Holder, C. (2011). Analysis of diesel particulate matter health risk disparities in selected US harbor areas. Am. J. Public Health 101, S217-S223. doi: 10.2105/AJPH.2011.300190

Sandifer, P. A., Keener, P., Scott, G. E., and Porter, D. E. (2021a). "Oceans and human health and the new blue economy," in Preparing a Workforce for the New Blue Economy, eds L. Hotaling and R. Spinrad (Amsterdam: Elsevier). (in press).

Sandifer, P. A., Walker, A. H., Finucane, M., Solo-Gabriele, H. M., Ferguson, A. E., Partyka, M., et al. (2021b). Human health and socioeconomic effects of the Deepwater Horizon oil spill in the Gulf of Mexico. Oceanography (in press).

Sandifer, P., Knapp, L., Lichtveld, M., Manley, R., Abramson, D., Caffey, R., et al. (2020). Framework for a community health observing system for the Gulf of Mexico region: preparing for future disasters. Front. Public Health 8:578463. doi: 10.3389/fpubh.2020.578463

Schlosberg, D., and Collins, L. B. (2014). From environmental to climate justice: climate change and the discourse of environmental justice. WIREs Clim. Chang. 5, 359-374.

Scott, C. H., Horton, C., Brett, C., Palmer, E., Pipes, S., Tufford, D., et al. (2019). Vibrio Bacteria in Aquatic Ecosystems: Effects of Climate Change on Antibiotic Resistance. Encyclopedia of Water: Science, Technology, and Society. Hoboken, NJ: Wiley Online Library. doi: 10.1002/9781119300762.wsts0226

Scott, G. I., Fulton, M. H., Weisberg, S. B., Muraya, K. A., and Lauenstein, G. (2012). Contaminants of emerging concern in the marine environment: the need for new monitoring and assessment strategies. J. Mar. Biol. Oceanogr. 1:1. doi: 10.4172/2324-8661.1000e102

Scott, G. I., Holland, A. F., and Sandifer, P. A. (2006). "Managing coastal urbanization and development in the 21st century: the need for a new paradigm," in Changing Land Use Patterns in the Coastal Zone: Managing Environmental Quality in Rapidly Developing Regions, eds G. Kleppel, M. R. DeVoe, and M. V. Rawson (New York, NY: Van Norstam Press), 285-299.

Siders, A. R. (2019a). Managed retreat in the United States. One Earth 1, 218-225. doi: 10.1016/j.oneear.2019.09.008

Siders, A. R. (2019b). Social justice implications of US managed retreat buyout programs. Clim. Chang. 15, 239-257. doi: 10.1007/s10584-018-2272-5

Siders, A. R., and Keenan, J. M. (2020). Variables shaping coastal adaptation decisions to armor, nourish, and retreat in North Carolina. Ocean Coast Manag. 183:105023. doi: 10.1016/j.ocecoaman.2019.105023

Siders, A. R., Hino, M., and Mach, K. J. (2019). The case for strategic and managed climate retreat. Science 365, 761-763. doi: 10.1126/science.aax8346

Silver, J. M., Arkema, K. K., Griffin, R. M., Lashley, B., Lemay, M., Maldonado, S., et al. (2019). Advancing coastal risk reduction science and implementation by accounting for climate, ecosystems, and people. Front. Mar. Sci. 6:556. doi: 10.3389/fmars.2019.00556

Sinay, L., and Carter, R. W. (2020). Climate change adaptations for coastal communities and local governments. Climate 8:7. doi: 10.3390/cli801 0007

Smith, E. A., Sweet, W., Mitchell, M., Domingues, R., Weaver, C. P., Baringer, M., et al. (2019). Treading water: tools to help US coastal communities plan for sea level rise impacts. Front. Mar. Sci. 6:300. doi: 10.3389/fmars.2019. 00300

Sutton-Grier, A. E., and Moore, A. (2016). Leveraging carbon services of coastal ecosystems for habitat protection and restoration. Coast. Manag. 43, 259-277.

Sutton-Grier, A. E., Gittman, R. K., Arkema, K. K., Bennett, R. O., Benoit, J., Blitch, S., et al. (2018). Investing in natural and nature-based infrastructure: building better along our coasts. Sustainability 10:523. doi: 10.3390/su1002 0253 
Sweet, W., Dusek, G., March, D., Carbin, G., and Marra, J. (2019). 2018 State of High Tide Flooding with a 2019 Outlook. NOAA Technical Report NOS COOPS 090. Washington, DC: National Oceanic and Atmospheric Administration, 31.

UN (United Nations) (2017). Fact Sheet. The Oceans Conference. New York, NY: United Nations, 2.

White, M. P., Elliott, L. R., Gascon, M., Roberts, B., and Fleming, L. E. (2020). Blue space, health and well-being: a narrative overview and synthesis of potential effects. Environ. Res. 191:110169. doi: 10.1016/j.envres.2020.11 0169
Conflict of Interest: The authors declare that the research was conducted in the absence of any commercial or financial relationships that could be construed as a potential conflict of interest.

Copyright (c) 2021 Sandifer and Scott. This is an open-access article distributed under the terms of the Creative Commons Attribution License (CC BY). The use, distribution or reproduction in other forums is permitted, provided the original author(s) and the copyright owner(s) are credited and that the original publication in this journal is cited, in accordance with accepted academic practice. No use, distribution or reproduction is permitted which does not comply with these terms. 